\title{
The Impact of C Reactive Protein in Prediction of the Outcome in Infective Endocarditis
}

\author{
Serap Şimşek-Yavuz ${ }^{\text {(D) }}$, Sibel Doğan-Kaya² (D), Denef Deniz ${ }^{3}$ D, Elif Tükenmez-Tigen ${ }^{4}$ (D) Serpil Öztürk ${ }^{\mathbf{5}}$ (D),

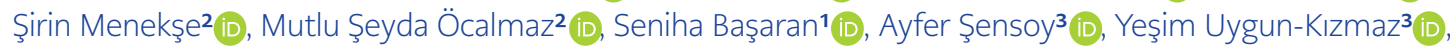

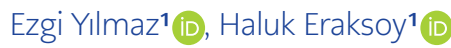 \\ 1 Department of Infectious Diseases and Clinical Microbiology, İstanbul University School of Medicine, İstanbul, Turkey. \\ 2 Kartal Koşuyolu Yüksek ihtisas Hospital, ìstanbul, Turkey. \\ 3 Siyami Ersek Thoracic and Cardiovascular Surgery Hospital, İstanbul, Turkey. \\ 4 Infectious Disease and Clinical Microbbiology Department, Marmara University School of Medicine, Istanbul, Turkey. \\ 5 Mehmet Akif Ersoy Thoracic and Cardiovascular Surgery Hospital, istanbul, Turkey.
}

\begin{abstract}
Objective: A simple and widely available test is needed to monitor the response to the treatment and predict adverse outcomes in patients with infective endocarditis (IE). We aimed to detect the role of C-reactive protein (CRP) level in the prognosis of IE.

Materials and Methods: The patients diagnosed as probable or definite IE between 2015 and 2016 from five medical centers were included in the study. Clinical and laboratory features of the patients recorded on previously prepared forms retrospectively. Comparison of CRP levels between survived and dead patients were made by repeated-measures variance analysis. Receiver operating characteristic (ROC) curves at baseline, the first, second, third and fourth week of antimicrobial treatment were constructed to explain the ability of CRP level to predict mortality. Multivariate analysis was performed to predict the risk factors for mortality.

Results: In total, 111 cases of IE were included. Serum CRP levels were higher in patients with mortality at every measurement. Comparing baseline CRP, lower than a double or triple decrease of serum CRP level at the third or fourth week of treatment or any increase under treatment were related to mortality. According to the ROC curve analysis, the highest overall accuracy in death prediction was at the fourth week CRP level (c=0.74); the CRP level of $\geq 50 \mathrm{mg} / \mathrm{L}$ was $86 \%$ sensitive and $78 \%$ specific to predict mortality. The presence of chronic renal failure (OR 14.386) and the fourth week CRP level (OR 1.016) were independent risk factors in terms of mortality.

Conclusion: Being an easily performed and widely available test, CRP is a useful tool to follow up the response to the treatment and predict outcome among patients with IE. In the fourth week of treatment, a CRP level of $\geq 50 \mathrm{mg} / \mathrm{L}$ should be regarded as an alarming sign of poor outcome and should lead to investigation and appropriate management of complications.
\end{abstract}

Keywords: Infective endocarditis, CRP, outcome
Corresponding Author:

Serap Şimşek-Yavuz

E-mail:

serapsimsekyavuz@gmail.com

Received: April 19, 2021

Accepted: April 25, 2021

Published: April 30, 2021

\section{Suggested citation:}

Şimşek-Yavuz S, Doğan-Kaya S, Deniz D, Tükenmez-Tigen E, Öztürk S, Menekşe S, et al. The Impact of C Reactive Protein in Prediction of the Outcome in Infective Endocarditis. Infect Dis Clin Microbiol 2021; 1: 1-7.

DOI: $10.36519 / \mathrm{idcm} .2021 .42$ 


\section{INTRODUCTION}

I nfective endocarditis (IE), among the most common life-threatening infection, is a serious disease causing substantial morbidity and mortality. Determining at-risk patients and following them up closely with appropriate interventions are necessary to decrease complications and mortality. Treatment response to infective endocarditis is followed up with the combination of relief of symptoms, blood cultures, echocardiographic investigations and laboratory tests (1). A simple and widely available test would be beneficial to monitor the treatment response and predict adverse outcomes. $C$ reactive protein (CRP) is a classical laboratory marker of inflammation and applied to monitor the behaviour of so many types of infections, including IE. However, most studies have focused on only baseline CRP levels. We analysed the clinical usefulness of serial CRP measurements in monitoring the therapy response and predicting the outcome of the disease in patients hospitalised for IE.

\section{MATERIALS AND METHODS}

All of the patients diagnosed as having probable or definite infective endocarditis according to Modified Duke Criteria (1) in the study centres of the members of Turkish Infectious Disease and Clinical Microbiology Society Infective Endocarditis Study Group between 2015 and 2016 included in the study. Demographic, clinical, laboratory, and therapeutic features of patients recorded on previously prepared forms retrospectively. Baseline and weekly CRP levels of patients recorded also. Comparison of CRP levels between survived and fatal cases were made by using repeated measures variance analysis. Receiver operating characteristic (ROC) curves at baseline, the first, second, third and fourth week of antimicrobial treatment were constructed to explain the ability of CRP level to predict mortality. In a ROC curve, sensitivity (y-axis) is plotted vs 1 minus specificity (x-axis) for each possible cut-off value of CRP level. Values are between 0.0 and 1.0 (higher values indicate a better accuracy), with 1.0 for a perfectly accurate test result and 0.5 for a test result that is not better than flipping a coin. The prognostic value of the per cent of decline from the baseline in CRP levels after 1, 2, 3 and 4 weeks of treatment were determined. The per cent of the decline in CRP level was calculated by dividing the CRP levels after 1, 2, 3 or 4 weeks of treatment by the baseline CRP level. Univariate analysis was done using Chi-square, Fisher's exact, Student's t, and Mann-Whitney U tests, where appropriate. Multivariate analysis was performed by logistic regression.

\section{RESULTS}

In total, 111 IE cases were included in the study. According to modified Duke Criteria, 86 and 25 of 111 patients were defined as definite and probable IE, respectively. The mean age was 55 , and $30 \%$ of the cases were female. One hundred of 111 (90\%) cases had left-sided IE. Demographic, clinical and laboratory features of patients were given in Table 1. Baseline CRP was higher than normal in 107 of 111 (97\%) patients with IE. CRP levels at baseline, the first, second, third and fourth weeks of the treatment were given in Table 2. For 51 patients, all five CRP measurements were available. Although all serum CRP levels were higher in patients with mortality than patients without mortality, the difference was statistically significant only for the second, third and fourth weeks of treatment (Table 3 and Figure 1). Comparing the baseline CRP level, lower than a double and triple decrease of serum CRP level at the third or fourth week of treatment, and any increase in serum CRP level after the beginning of the treatment was found to be related to mortality $(p=0.040,0.009,0.0400 .033$, and 0.017, respectively).

By ROC analysis for CRP levels at baseline and the first to fourth weeks of treatment to predict poor outcome in patients with IE, the highest overall accuracy (area under the ROC curve, c-index) in the prediction of death was found for the fourth week CRP level ( $c=0.74,95 \%$ confidence interval

\section{HIGHLIGHTS}

- CRP is a useful tool to follow up the treatment response and predict outcome among patients with infective endocarditis (IE)

- A CRP level of higher than $50 \mathrm{mg} / \mathrm{L}$ in the fourth week of treatment should be regarded as an alarming sign of the poor outcome

- CRP should be measured at least weekly during the treatment of patients with IE 

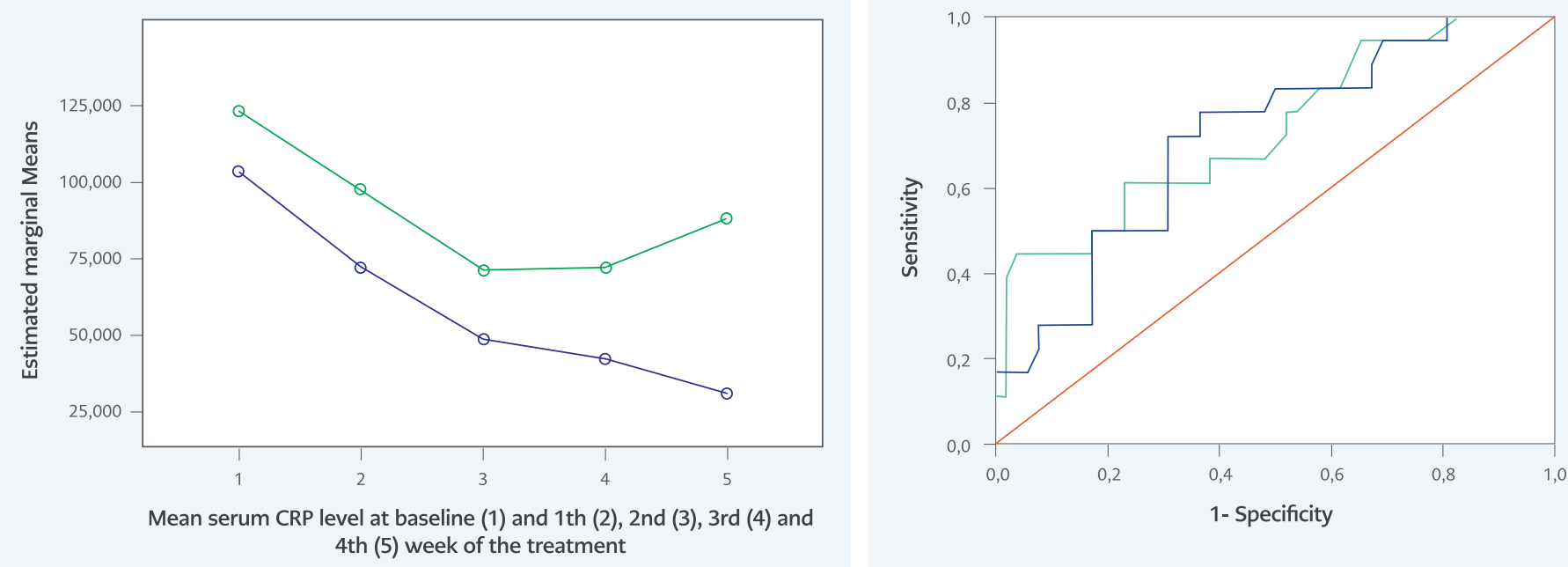

Sources of the Curve

Mean level of serum CRP level at the 3rd week of treatmet Mean level of serum CRP level at the 4th week of treatmet

Figure 1. Comparison of baseline (1) and weekly $(2,3,4,5)$ mean serum CRP levels during treatment between patients who died or survived.

[CI], 0.61-0.88, $p=0.001)$, the second highest was for the third week ( $c=0.68,95 \%$ [CI] 0.56-0.81, p=0.006), and the lowest at baseline ( $\mathrm{c}=0.55,95 \%$ [CI] 0.42$0.68, \mathrm{p}=0.37$ ). The area under the ROC curve was 0.60 (95\% [CI], 0.52-0.74, p=0.09) one week after the beginning of antimicrobial therapy and 0.60 (95\% CI, 0.47-0.73, p=0.12) two weeks later (Figure 2). We searched for cut-off points of $\mathrm{C}$-reactive protein in week three and four that could predict the death of a patient during the remaining follow-up with a sensitivity of at least $85 \%$ combined with the best possible specificity. A serum CRP concentration of $50 \mathrm{mg} / \mathrm{L}$ was identified as such a cut-off point. In week four, the CRP value was $\geq 50 \mathrm{mg} / \mathrm{L}$ in 14 out of the 16 patients (sensitivity 86\%) who died during the remaining follow-up, whereas the C-reactive protein value was $<50 \mathrm{mg} / \mathrm{L}$ in 34 of the 44 patients (specificity 78\%) who survived (Table 4).

In univariate analysis, age $(\mathrm{p}=0.05)$, female gender $(p=0.03)$, presence of chronic renal failure before the diagnosis of IE $(\mathrm{p}=0.02)$, baseline serum creatinine $(p=0.001)$ and albumin $(p=0.012)$ levels, causative microorganism other than streptococci $(p=0.039)$, healthcare-associated infections $(\mathrm{p}=0.02)$, serum CRP level in the third and fourth week of treatment were related to mortality. In the multivariate analysis by logistic regression, the presence of chronic renal failure (OR 14.38, 95\% [CI] 1.29-160.42, $\mathrm{p}=0.030$ ) and CRP level in the fourth week of treatment (OR $1.016,95 \%$ [CI] 1.004-1.028, $\mathrm{p}=0.009$ ) were the significant predictors of the fatality.

\section{DISCUSSION}

Baseline CRP was almost exclusively high in patients with IE in previous studies (2) so that some investigators proposed modifying the Duke criteria to include a CRP level of more than $100 \mathrm{mg} / \mathrm{L}$. However, CRP is a non-specific marker that can increase because of many infectious or non-infectious diseases, and we did not accept it as a diagnostic criterion (2). Follow-up of patients with endocarditis is difficult and generally relies on the combination of clinical response, control blood culture negativity, and decrease in vegetation size. Nevertheless, endocarditis is not a uniform disease, and in the case of blood culture negativity, or subacute/ chronic presentation or no vegetation decrease 
Table 1. Demographic, Clinical and Laboratory Features of Infective Endocarditis Cases.

\begin{tabular}{|c|c|}
\hline Features & Result \\
\hline Age, mean (SD) & $55(16)$ \\
\hline Gender, female, n (\%) & 30 \\
\hline Duration of complaints, mean (SD) & $72(131)$ \\
\hline Acute rheumatic heart valve disease, $n(\%)$ & $13(12)$ \\
\hline Prosthetic valve, n (\%) & $36(33)$ \\
\hline Pace/ICD lead endocarditis, n (\%) & $9(8)$ \\
\hline IV drug user, n (\%) & $4(4)$ \\
\hline Haemodialysis, n (\%) & $14(13)$ \\
\hline \multicolumn{2}{|l|}{ Complaints } \\
\hline Fever, $\mathrm{n}(\%)$ & $81(73)$ \\
\hline Fatigue, n (\%) & $70(63)$ \\
\hline Dyspnea, n (\%) & $36(32)$ \\
\hline Joint, muscle pain, n (\%) & $17(15)$ \\
\hline Change in conscious, $n$ (\%) & $16(14)$ \\
\hline Weight loss, n (\%) & $12(11)$ \\
\hline \multicolumn{2}{|l|}{ Physical investigation findings } \\
\hline Fever, n (\%) & 75 (68) \\
\hline Tachycardia, n (\%) & $70(64)$ \\
\hline Splenomegaly, n (\%) & $16(14)$ \\
\hline Hypotension, n (\%) & $8(7)$ \\
\hline Congestive heart failure, $\mathrm{n}(\%)$ & $31(28)$ \\
\hline Embolic event, $\mathrm{n}(\%)$ & $30(27)$ \\
\hline Vegetatiton in echocardiography, n (\%) & $93(84)$ \\
\hline Vegetatiton size, $\mathrm{mm}^{2}$, mean (SD) & $149(144)$ \\
\hline Definition of causative microorganisms, n (\%) & 70.5 \\
\hline Streptococcus spp., n (\%) & $24(22)$ \\
\hline Staphylococcus aureus, n (\%) & $16(15)$ \\
\hline Enterococus spp., $\mathrm{n}(\%)$ & $9(8)$ \\
\hline RF positivity, $\mathrm{n}(\%)$ & $20(18)$ \\
\hline Haematuria, n (\%) & $40(36)$ \\
\hline Blood WBC count/ $\mu \mathrm{L}$, mean (SD) & $11517(5154)$ \\
\hline Blood hemoglobin level, mean (SD) & $10.5(1.9)$ \\
\hline Blood platelet count / $\mu \mathrm{l}$, , mean (SD) & $235(119)$ \\
\hline Mean Platelet Volume (MPV), mean (SD) & $8.43(1.09)$ \\
\hline ESR, mean (SD) & $68(26)$ \\
\hline Baseline serum CRP level, mg/L mean (SD) & $112(94)$ \\
\hline Serum SGPT level mg/dL, mean (SD) & $43.27(116.61)$ \\
\hline Serum creatinin level, mg/dL, mean (SD) & $1.63(1.74)$ \\
\hline Blood sugar level , mg/dL mean (SD) & $137.10(79.10)$ \\
\hline Serum albumin level, gr/dL, mean (SD) & $3.18(2.30)$ \\
\hline Serum troponin level, mean (SD) & $4.46(26.68)$ \\
\hline Surgical intervention for endocarditis, n (\%) & $62(56)$ \\
\hline Recurrence, $\mathrm{n}(\%)$ & $8(7)$ \\
\hline Mortality, n (\%) & $31(28)$ \\
\hline
\end{tabular}

with treatment, some other parameters are needed to follow up the treatment response and good outcome. Being almost always positive in patients with endocarditis and as an easily performed and widely available test, CRP could be a useful tool to follow the treatment response and predict the outcome. CRP level could be used as a marker to evaluate treatment response in patients with IE, but it should be known that decrease time is long and generally takes several weeks. In our study, the median level of CRP was 87, 65, 43, 36 and 19 at baseline and in the first, second, third and fourth weeks of the treatment, respectively. It was previously reported that a mean of 13 days is required for the CRP concentration to return to normal once treatment was started (3). CRP levels of patients at baseline and in the first, second, third and fourth weeks of the treatment were higher in patients with mortality than patients without mortality, which was statistically significant for the second, third and fourth week's CRP levels. Although many studies reported that baseline CRP was an independent predictor of death $(4,5,6)$, few studies investigated the value of serial CRP measurements during antimicrobial treatment (7). Comparing the baseline CRP level, lower than a double and triple decrease of serum CRP level at the third or fourth week of the treatment and any increase of serum CRP level after the beginning of the treatment were related to mortality in our study. High CRP level after 1 week of treatment and a slow percentage decline in CRP level during the first week of treatment were found to be indicators of poor clinical outcome also in a prospective study of 123 definite leftsided native valve infective endocarditis from Holland (7). The highest overall accuracy in the prediction of death was found for the fourth week CRP $(c=0.74)$, it was followed by the third week ( $c=0.68)$, the first week $(c=0.60)$, the second week $(c=0.60)$ and baseline CRP $(c=0.55)$. The cut-off point of CRP that could predict the death of a patient during the remaining follow-up was $50 \mathrm{mg} / \mathrm{L}$ at week four with a sensitivity of $86 \%$ and specificity of $78 \%$ in our study. In another study aiming to investigate the value of a panel of biomarkers for predicting in-hospital mortality in patients with IE, CRP ( $\mathrm{c}=0.75$ ) had good accuracy for predicting death after seven days of antibiotic therapy (8). The other study from India found that a high baseline CRP level was independently pre- 
Table 2. CRP Levels of Patients at Baseline, 1 th, $2^{\text {nd }}, 3^{\text {rd }}$ and $4^{\text {th }}$ Week's of Treatment.

\begin{tabular}{|c|c|c|c|c|c|c|}
\hline \multicolumn{2}{|c|}{$\begin{array}{l}\text { Serum CRP } \\
\text { level mg/L (n) }\end{array}$} & Baseline (99) & $\begin{array}{l}1^{\text {th }} \text { week of } \\
\text { treatment }(101)\end{array}$ & $\begin{array}{l}2^{\text {nd }} \text { week of } \\
\text { treatment } \\
\text { (93) }\end{array}$ & $\begin{array}{c}3^{\text {rd }} \text { week of } \\
\text { treatment } \\
\text { (85) }\end{array}$ & $\begin{array}{c}4^{\text {th }} \text { week of } \\
\text { treatment } \\
\text { (75) }\end{array}$ \\
\hline \multicolumn{2}{|l|}{ Mean } & $111 \pm 94$ & $6 \pm 56$ & $57 \pm 55$ & $56 \pm 55$ & $49 \pm 70$ \\
\hline \multirow{3}{*}{ Percentiles } & 25 & 47 & 26 & 16 & 18 & 8 \\
\hline & 50 & 87 & 65 & 43 & 36 & 19 \\
\hline & 75 & 148 & 115 & 81 & 90 & 47 \\
\hline
\end{tabular}

Table 3. Comparison of CRP Levels Between Infective Endocarditis Patients With and Without Mortality.

\begin{tabular}{|c|c|c|c|c|}
\hline CRP level (mg/L) (range) & Total (n) & $\begin{array}{l}\text { Patients without } \\
\text { mortality (n) }\end{array}$ & $\begin{array}{l}\text { Patients with } \\
\text { mortality (n) }\end{array}$ & $\mathrm{P}$ \\
\hline CRP, baseline, mean $\pm S D(2-614)$ & $111.99 \pm 94.91(99)$ & $101.39 \pm 75.77(70)$ & $119.89 \pm 90.78(29)$ & 0.379 \\
\hline CRP, $1^{\text {th }}$ week of treatment, mean \pm SD $(1-267)$ & $76.32 \pm 56.94(101)$ & $69.47 \pm 54.92(71)$ & $88.17 \pm 56.73(30)$ & 0.093 \\
\hline CRP, $2^{\text {nd }}$ week of treatment, mean $\pm S D(0-247)$ & $57.90 \pm 55.06(93)$ & $51.50 \pm 48.35(66)$ & $73.54 \pm 67.10(27)$ & 0.121 \\
\hline CRP $3^{\text {rd }}$ week of treatment, mean \pm SD $(1-240)$ & $56.34 \pm 55.06(85)$ & $44.50 \pm 45.88(58)$ & $81.75 \pm 64.77(27)$ & 0.006 \\
\hline CRP $4^{\text {th }}$ week of treatment, mean \pm SD $(1-320)$ & $49.64 \pm 70.89(75)$ & $29.85 \pm 37.99(56)$ & $107.97 \pm 106.96(19)$ & 0.001 \\
\hline
\end{tabular}

Table 4. Definition of Cut-Off Points of CRP, on Week 3 and 4 That Could Predict Death of A Patient During the Remaining Follow-Up.

\begin{tabular}{|c|c|c|c|c|c|}
\hline \multicolumn{2}{|c|}{ CRP breakpoint level mg/L } & Sensitivity, \% & Specificity, \% & PPV, \% & NPV, \% \\
\hline \multirow{2}{*}{$>10$} & $3^{\text {rd }}$ week of treatment & 19 & 89 & 79 & 34 \\
\hline & $4^{\text {th }}$ week of treatment & 38 & 90 & 91 & 33 \\
\hline \multirow{2}{*}{$>20$} & $3^{\text {rd }}$ week of treatment & 41 & 82 & 83 & 39 \\
\hline & $4^{\text {th }}$ week of treatment & 57 & 68 & 84 & 35 \\
\hline \multirow{2}{*}{$>30$} & $3^{\text {rd }}$ week of treatment & 57 & 78 & 85 & 46 \\
\hline & $4^{\text {th }}$ week of treatment & 64 & 63 & 84 & 38 \\
\hline \multirow{2}{*}{$>40$} & $3^{\text {rd }}$ week of treatment & 66 & 70 & 83 & 49 \\
\hline & $4^{\text {th }}$ week of treatment & 77 & 58 & 84 & 46 \\
\hline \multirow{2}{*}{$>50$} & $3^{\text {rd }}$ week of treatment & 71 & 56 & 77 & 47 \\
\hline & $4^{\text {th }}$ week of treatment & 86 & 78 & 83 & 56 \\
\hline \multirow{2}{*}{$>60$} & $3^{\text {rd }}$ week of treatment & 74 & 55 & 78 & 50 \\
\hline & $4^{\text {th }}$ week of treatment & 89 & 47 & 83 & 60 \\
\hline \multirow{2}{*}{$>70$} & $3^{\text {rd }}$ week of treatment & 81 & 57 & 80 & 58 \\
\hline & $4^{\text {th }}$ week of treatment & 91 & 47 & 84 & 64 \\
\hline
\end{tabular}


dictive of mortality, major complications, embolic events, and need for urgent surgery, and also a CRP $>40 \mathrm{mg} / \mathrm{l}$ predicted adverse outcomes with a sensitivity of $73 \%$ and specificity of $99 \%$ (9). Similar to our results, in the study of Heiro et al., within the three laboratory tests (ESR, CRP and WBC) at week four, CRP had the highest overall accuracy (area under ROC curve, c-index) in the prediction of death among patients with IE ( $\mathrm{c}=0.77$ ); the cut-off point of CRP concentration to predict mortality with $85.7 \%$ sensitivity and $72.5 \%$ specificity was identified as CRP $62 \mathrm{mg} / \mathrm{L}$ (10).

Since our study was retrospective, CRP measurements at different time points were not available for all patients. However, availability was ranged from $67 \%$ to $90 \%$ at each time-point. Some potential risk factors for mortality might not be recorded because of the retrospective study design, but we included all the available demographic, clinical, and laboratory data to analyse the mortality.

Besides these limitations, our study has some strengths. We included more than a hundred of pa- tients from five significant medical centers, which enabled us to represent so many different types of infective endocarditis cases including native and prosthetic valve, right and left sided endocarditis. Also, the clinical usefulness of baseline and four different time point CRP measurements in monitoring the response to therapy and predicting the outcome of the disease in patients with hospitalised for IE were analysed in our study.

\section{CONCLUSIONS}

Being an easily performed and widely available test, CRP is a useful tool to follow up the response to the treatment and predict outcome among patients with IE. CRP should be measured at least weekly during the treatment of patients with IE. A CRP level higher than $50 \mathrm{mg} / \mathrm{L}$ at the fourth week of treatment should be regarded as an alarming sign of poor outcome and should lead to investigation and appropriate early management of complications. The prediction of poor outcome and prevention of it with appropriate measures will decrease the death rate among patients with IE.
Ethical Approval: Ethical Committee of Istanbul University Istanbul Faculty of Medicine approved the study on April 6, 2020 with the decision number of 187748 .

Peer-review: Externally peer-reviewed

Author Contributions: Concept - S.Ş.Y; Design - S.Ş.Y., S.B.; Supervision - S.Ş.Y.; Fundings - S.D.K., D.D., E.T.T., S.O., Ş.M., M.Ş.Ö., A.Ş. , Y.U.K., E.Y.; Materials - Data Collection and/or Processing - S.D.K., D.D., E.T.T., S.Ö., Ş.M., M.Ş.Ö., A.Ş. ; Analysis and/or
Interpretation -Y.U.K, E.Y., S.S.Y., S.B.; Literature Review - S.Ş.Y., S.B.; Writer - S.Ş.Y., H.E.; Critical Reviews - S.Ş.Y., H.E.

Conflict of Interest: The authors have no conflict of interest to declare.

Financial Disclosure: This work was supported by the Scientific Research Projects Coordination Unit of İstanbul University (Project Number:BEK-2017-25828).

\section{REFERENCES}

1 Baddour LM, Wilson WR, Bayer AS, Fowler VG Jr, Tleyjeh IM, Rybak MJ, et al. Infective endocarditis in adults: diagnosis, antimicrobial therapy, and management of complications: a scientific statement for healthcare professionals from the American Heart Association. Circulation 2015; 132: 1435-86

2 Watkins RR, Lemonovich TL. Role of inflammatory markers in the diagnosis and management of infective endocarditis. Infect Dis Clin Pract 2010;18: 87-90

3 McCartney AC, Orange GV, Pringle SD, Wills G, Reece IJ. Serum
C reactive protein in infective endocarditis. J Clin Pathol 1988; 41: 44-8.

4 Nunes MCP, Guimarães-Júnior MH, Murta Pinto PHO, Coelho RMP, Souza Barros TL, Faleiro Maia NPA, et al. Outcomes of infective endocarditis in the current era: Early predictors of a poor prognosis. Int J Infect Dis 2018; 68: 102-7.

5 Cornelissen CG, Frechen DA, Schreiner K, Marx N, Krüger S. Inflammatory parameters and prediction of prognosis in infective endocarditis. BMC Infect Dis 2013; 13: 272. 
6 Tascini C, Aimo A, Arzilli C, Sbrana F, Ripoli A, Ghiadoni L, et al Procalcitonin, white blood cell count and C-reactive protein as predictors of $\mathrm{S}$. aureus infection and mortality in infective endocarditis. Int J Cardiol 2020; 301:190-4.

7 Verhagen DW, Hermanides J, Korevaar JC, Bossuyt PM, van den Brink RB, Speelman P, et al. Prognostic value of serial C-reactive protein measurements in left-sided native valve endocarditis. Arch Intern Med 2008; 168: 302-7.

8 Siciliano RF, Gualandro DM, Bittencourt MS, Paixão M, Marcondes-Braga F, Soeiro AM, et al. Biomarkers for prediction of mortality in left-sided infective endocarditis. Int J Infect Dis 2020; 96: 25-30.
9 Mohanan S, Gopalan Nair R, Vellani H, C G S, George B, M N $\mathrm{K}$. Baseline C-reactive protein levels and prognosis in patients with infective endocarditis: a prospective cohort study. Indian Heart J 2018; 70 Suppl 3: S43-S49.

10 Heiro M, Helenius H, Sundell J, Koskinen P, Engblom E, Nikoskelainen J, et al. Utility of serum C-reactive protein in assessing the outcome of infective endocarditis. Eur Heart J; 26: 1873-81. 